\title{
ATTAINING EFFICIENCY IN CITY SCHOOL SYSTEMS
}

\author{
By Frank P. Bachman, Ph.D.,
}

Of the Committee on School Inquiry, New York City.

Efficiency in education implies standards of efficiency and detailed knowledge of the results achieved.

\section{Standards of Judging of the Efficiency of a City School System}

The final test of whether a school system is doing its work well lies in whether it is giving to the community supporting it young men and women prepared to take their place and do their part in the life about them. Whether the young people now coming from our schools possess the health, the kind of knowledge, the degree of skill, and the qualities of character required in the immediate future, of strong men and women, can only be determined, if at all, after these young people have been out in the world from five to ten years, or even longer. To make the ultimate test of education the basis of judging the present efficiency of a school system is consequently out of the question. Hence the necessity of fixing upon and applying other criteria.

The idea that school work can or should be subject to efficiency tests is still foreign to most of the men and women engaged in education. Only here and there has the idea found acceptance and has the need of efficiency standards been felt. As a result but few such standards have been developed. Indeed, at the present time, we scarcely know what constitutes efficiency even in such formal studies as arithmetic, spelling and writing, to say nothing of having fixed upon definite standards by which to judge the efficiency of a city school system. Any standard proposed at the present time as measures of the efficiency of a city school system must therefore be very general in character.

We, however, believe it will be generally accepted that that school system is most efficient:

(a) which reaches the largest proportion of the children of the community of school age; 
(b) which succeeds at the same time in giving to the largest proportion of the children of the community a complete elementary education, if not a complete high school education;

(c.) which gives at the same time to the children of the community the best quality of elementary and high school education;

(d) which educates the children of the community, when everything is taken into account, at the smallest cost to the taxpayer.

\section{Attaining Efficiency: Reaching the Children of the Community}

Before a city school system can be judged with reference to the extent to which it is reaching the children of the community of school age, and before definite steps can be taken to increase efficiency in this direction, knowledge must be had of the number of children in the community who ought to be in school.

The compulsory attendance laws of most of the states require that all children between the ages of seven and fourteen be in attendance during the whole time the school is in session. To malke sure that children have at least the opportunity to gain a complete elementary education, the laws of some of the states compel children under sixteen years of age, who have not graduated from the elementary school, to attend school for at least a given number of days each week. Most states do not stop, however, with making school attendance compulsory upon all to the fourteenth year and with compelling children who have not graduated from the elementary school to attend until sixteen, but of such worth is education deemed to be to the individual and of such importance to the state that it is made obligatory upon the community to afford to its children the opportunity of securing at public expense a high school education. In a word, it is generally accepted that the interests of the individual and the needs of a democratic society like ours demand that all children from six to fourteen years of age should be in regular attendance on the elementary school and that all children between fourteen and eighteen should be in high school.

There is, however, scarcely a city in the United States that has accurate knowledge of the number of children in the community between the ages of six and eighteen, and has this knowledge so 
ordered that it may be made to serve as the basis of judging of the efficiency of the school. To be sure, the state laws require in many places a so-called annual school enumeration, but these enumerations are, as a rule, both inaccurate and incomplete, and, in most cases, it is impossible so to arrange the data collected as to show the number of children in the community of each of the several ages between six and eighteen, to the end that comparisons may be made between the number of children of a given age that ought to be in school and the number of such children that are in schooi. Further, the annual reports of most city school systems show the increase in enrollment year over year, and this increase is pointed to as evidence of increasing efficiency. But such data throw no light whatever upon efficiency. Indeed, in centers of rapidly increasing population, the schools may show an increased enrollment from year to year, and yet they may be reaching relatively fewer and fewer of the children of school age.

The first step in attaining efficiency in a city school system is, therefore, to secure an accurate school census which shows the children of each age between six and eighteen. A comparison of these data with the total enrollment by ages, in public, private, and parochial schools will reveal what proportion of the children of the community of each age are being reached by each kind of school; what proportion are not being reached by any school; and the proportion being reached by the public school.

Table I shows the school census, by ages, of the city of Cleveland for 1908-1909, the number enrolled in public, private and parochial schools, the number in no school, the per cent in no school, and the per cent of all the children of the city in the public school.

It will be noted that the sum of the children enrolled in 19081909 in the public schools of Cleveland and those claiming attendance in private and parochial schools is greater for the years six, eight, nine, ten, eleven and thirteen, than the total number of children of these ages reported in the school enumeration, which suggests that the school census is incomplete, and in nowise gives all the children in the city of a given age.

However this may be, it appears that the school breaks down even before the fifteenth year. Indeed, to such an extent does the school fail to attract, that 26.69 per cent of the children fourteen years oid, 56.01 per cent of those fifteen, 73.45 per cent of those 


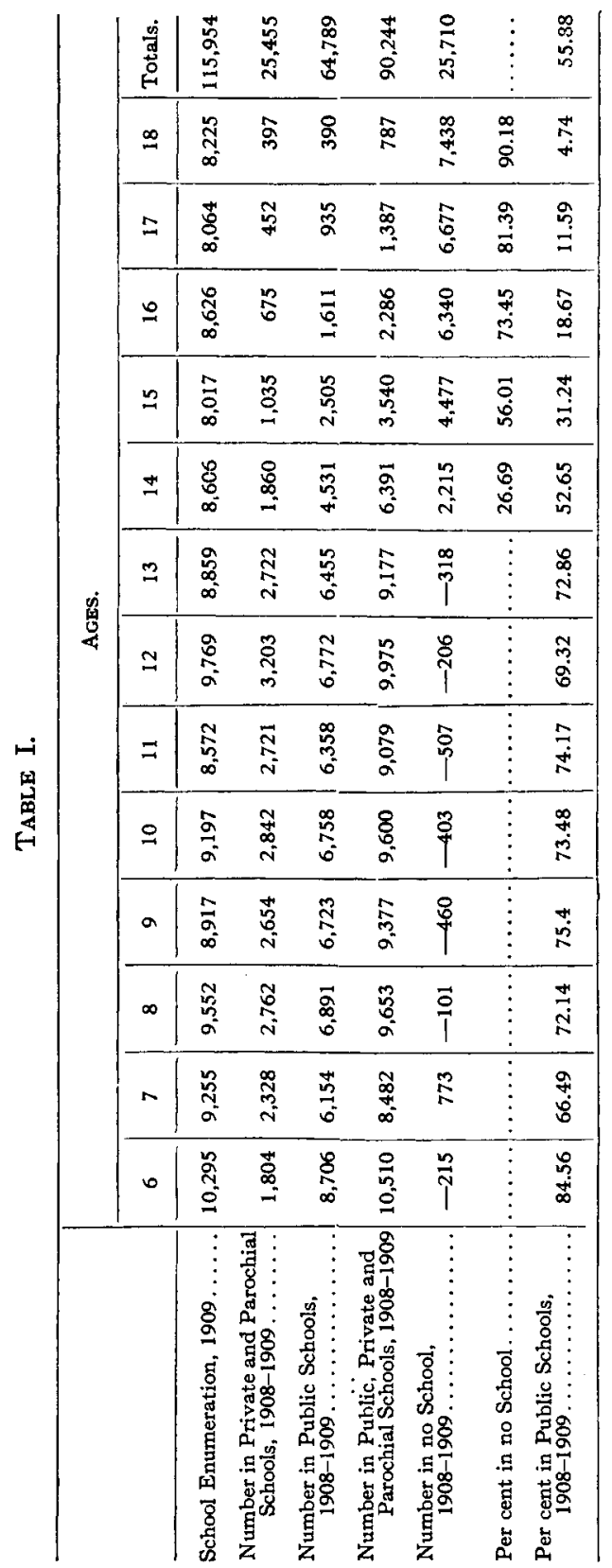


sixteen, 81.39 per cent of those seventeen, and 90.18 per cent of those eighteen years of age, are neither in public, private nor parochial schools. Of the children fourteen to eighteen, sixty-five out of every hundred are subject to no school influence whatsoever, and at a period of life, too, when children are most plastic, when the foundations of future efficiency are laid, when habits controlling later action are fixed, when attitudes of mind are formed, and character is determined. Worse still, of the children between fourteen and sixteen, inclusive, not one child in two attends school, and this at a time when, as shown by the Massachusetts Industrial Commission, the child is practically industrially worthless-an economic loss and a loss in human worth and happiness permitted nowhere else save in prodigal America.

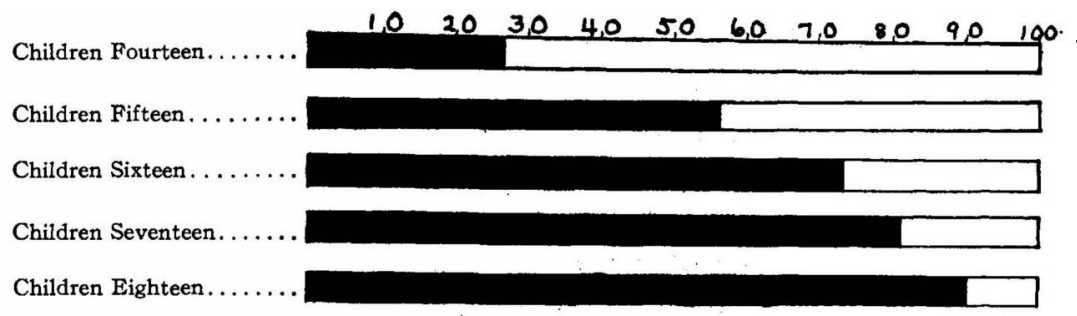

FIG. 1.-Black shows per cent of all the children of Cleveland of each age from fourteen to eighteen attending no school whatsoever in 1908-09.

It would therefore seem that, on the whole, public, private and parochial schools in Cleveland together are reaching to a greater or less extent the children of the community between six and thirteen, inclusive, yet were the facts at hand, these would doubtless show that a considerable number of children eleven, twelve and thirteen attend no school, and when it comes to children beyond thirteen, it can be said unhesitatingly, that all the education institutions of the city, together, are accomplishing but slightly more than half of the whole task of the school, that is, they are reaching but few more than half of the children of the city between the ages of fourteen and eighteen.

The public schools of Cleveland alone, it will be observed, are reaching in one way or another but 56 per cent of all the children 
of the community between the ages of six and eighteen. Of the children between six and fourteen, the elementary school is reaching only 71.48 per cent, while the high school is bringing under its influence but 16.52 per cent of those between fifteen and eighteen.

To be sure, the public school is not the only institution that can give a good education, yet the fact that 29 per cent of the children of the community are receiving their elementary education apart from the public school, and that 65 per cent of the youth of the city between fourteen and eighteen are receiving no public school education whatsoever, is worthy of attention and serious consideration.

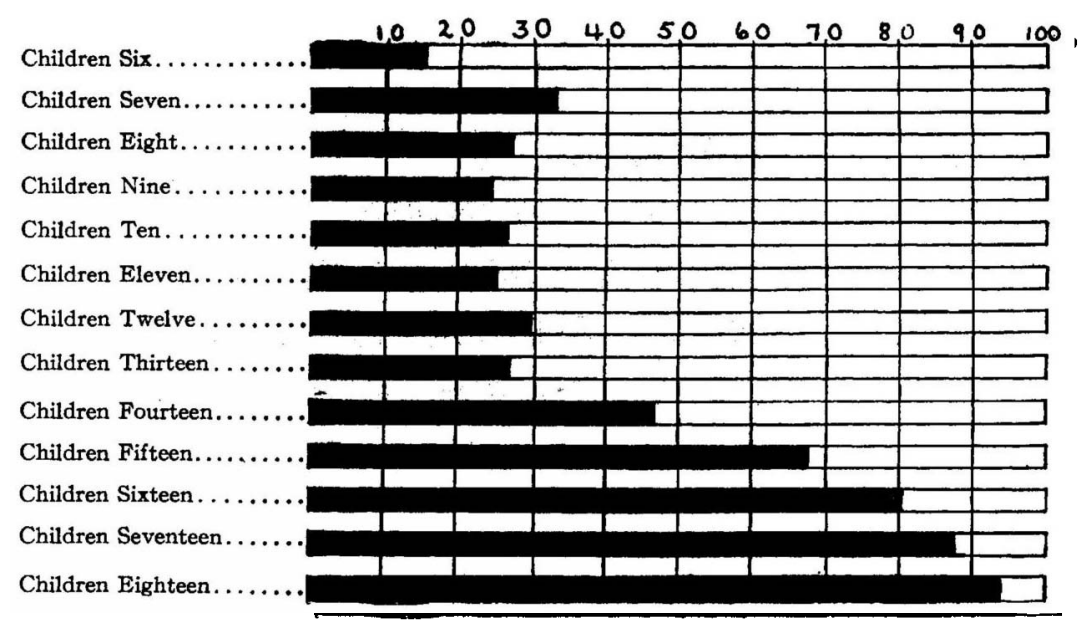

FIG. 2.-Black shows per cent of all the children of Cleveland of each age from six to eighteen not attending the public school in 1908-09.

Whatever opinion may be held with regard to the schools of a given city, a school census such as the foregoing gives a definite picture of the number of the children of each age to be reached, the number of each age reached, and the number of each age not reached; it also supplies data needed in planning improvements, and, when taken in connection with the census for other years, supplies the basis of judging whether or not the efficiency of the system with respect to reaching the children of the community is increasing or decreasing. 


\section{Attaining Efficiency: Holding the Children in School}

An efficient school system must not only reach all the children of the community, but, in view of our second standard of efficiency, it must also hold children in school until they have gained a complete elementary, if not, a complete high school education. Hence the efficiency of a school system may be measured by the number of grades completed by children before they drop out permanently. The number of grades a child completes depends, however, very largely upon the number of years he remains in school, and upon the regularity of his attendance.

\section{Increasing the Number of Days Attended During the School Year}

Irregular attendance has seldom been looked upon as a measure of the school; it has been more often regarded as a delinquency of the child. However that may be, that school system is undoubtedly the most efficient which holds its pupils in school the largest number of days in the school year.

TABLE II.

\begin{tabular}{|c|c|c|}
\hline Attending. & Pupils. & $\begin{array}{l}\text { Per cent of } \\
\text { Enrollment. }\end{array}$ \\
\hline  & $\begin{array}{r}1,312 \\
34,908 \\
12,930 \\
6,099 \\
3,746 \\
2,797 \\
3,165 \\
2,570 \\
2,696 \\
2,772 \\
2,564\end{array}$ & $\begin{array}{r}1.74 \\
46.20 \\
17.11 \\
8.07 \\
4.96 \\
3.70 \\
4.19 \\
3.40 \\
3.57 \\
3.67 \\
3.39\end{array}$ \\
\hline Total........ & 75,559 & 100.00 \\
\hline
\end{tabular}

Attendance records are universally kept, but the chief use made of such records is, as a rule, to report on average daily attendance. Attendance reports which give only average daily attendance are valueless. To be of value, whether they be for the month or for the year, they must show the number of days each child is in at- 
tendance. The reports of St. Louis are illustrative. Table II shows the number of days each child was in attendance in the elementary schools of St. Louis (white districts only) during the school year 1909-1910.

Whatever the per cent of average daily attendance reported by this or that city school system, it would appear from Table II that children in large numbers attend school only a small portion of the year. Each tenth child enrolled in the St. Louis schools in



Fig. 3.-Black shows for 1909-10 the per cent of the total enrollment in St Louis (white districts only) absent more than 180 days, more than 160 days, etc.

1909-1910 was actually in school less than sixty days; while one child out of each five attended less than half the time. Such facts, by recording actual conditions, not only show the need of making strenuous effort to hold more children in school a larger number of days, but also show the range of improvement.

With data such as are given in Table II at hand by months for each school in the system the weak schools may be located, and by studying conditions in these weak schools such changes may 
be made as will materially increase attendance. Moreover, if data like those in Table II are collected and tabulated for the system as a whole for a number of years they become a reliable basis of judging whether the system is gaining or losing in holding power.

Table III shows for the elementary schools of St. Louis (white districts only) for the years 1906-1910 the per cent of the enrollment attending 200 days, 180 to 200 days, and so on.

\section{Increasing the Number of Grades Completed}

A city school system has attained a maximum of efficiency, in view of our second standard, only when it is giving to all the children of the community a complete elementary if not a complete

TABLE III.

\begin{tabular}{|c|c|c|c|c|c|}
\hline Attending. & $1905-6$ & $1906-7$ & $1907-8$. & $1908-9$. & $1909-10$. \\
\hline 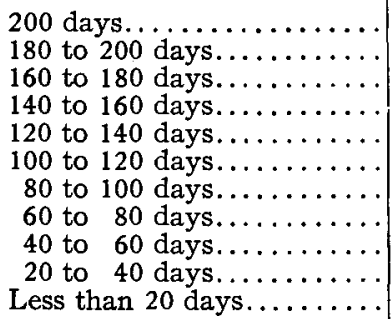 & $\begin{array}{r}4.66 \\
45.86 \\
13.83 \\
7.26 \\
4.48 \\
4.25 \\
5.03 \\
3.29 \\
3.85 \\
3.73 \\
3.76\end{array}$ & $\begin{array}{r}4.44 \\
43.14 \\
15.76 \\
7.63 \\
4.86 \\
4.21 \\
4.39 \\
3.51 \\
3.97 \\
4.33 \\
3.76\end{array}$ & $\begin{array}{r}3.44 \\
45.76 \\
15.95 \\
7.73 \\
4.65 \\
3.80 \\
3.87 \\
3.27 \\
3.86 \\
4.43 \\
3.24\end{array}$ & $\begin{array}{r}3.11 \\
45.09 \\
17.40 \\
8.19 \\
4.96 \\
3.84 \\
3.97 \\
3.43 \\
3.45 \\
3.36 \\
3.20\end{array}$ & $\begin{array}{r}1.74 \\
46.20 \\
17.11 \\
8.07 \\
4.96 \\
3.70 \\
4.19 \\
3.40 \\
3.57 \\
3.67 \\
3.39\end{array}$ \\
\hline
\end{tabular}

high school education. How far we are at present from this degree of efficiency is suggested by Dr. Leonard P. Ayres who estimates that on the average 49 per cent of the children entering the schools of fifty-nine cities of the country never go beyond the seventh grade of the elementary school, while Dr. Edward L. Thorndike estimates that on the average, in sixteen of our largest cities, but 33 per cent ever enter the eighth grade.

Until very recently no attention was given to how much education the children of the community were actually receiving, and even after a decade of agitation not more than two or three large cities have as yet taken any steps to find out these facts. Obviously, if school authorities are to know where the school breaks down, if 
they are to make intelligent changes in the system in view of better adapting it to the needs of all the children, and if they are to have at hand the means of judging whether or not there is an increase in efficiency, records must be provided and data collected year by year on the number of terms of work to the credit of pupils leaving the school permanently. Cleveland has made a beginning in this direction.

Table IV shows the life history in numbers of the pupils entering the first grade of the public schools of Cleveland for each of the years 1889-1898, and shows what per cent of the pupils enrolled in the first grade during these ten years completed less than two grades, less than three grades, and so on through the elementary and high school.

It will be observed, when the official records are taken as the basis of judgment, that, for the ten year period under consideration, of all the pupils enrolled in the first year classes, 28.5 per cent completed in the public schools of Cleveland less than two grades, 29.5 per cent completed less than three grades, 31.8 per cent less than four grades, 42.9 per cent less than five grades, 53.8 per cent less than six grades, 64.9 per cent less than seven grades, 75 per cent failed to complete the elementary school, 84.5 per cent failed to finish the first year in high school, 89.6 per cent to finish the second year, 92.4 per cent the third year, and 94.8 per cent failed to graduate from high school.

In other words, half of the citizens of Cleveland, when judged by the records of the public schools, are taking up the duties of life with only the education afforded by the fifth grade, but one in four has enjoyed a complete elementary education, and less than one in seven has to his credit any high school work whatsoever-a condition which raises social and civic questions of the gravest character.

With these and other facts before them, the school authorities of Cleveland instituted a number of important changes. In the elementary schools the course of study was simplified; the number of classes for defective pupils was increased; a system of quarterly promotions was installed; a method of promotion was instituted which both takes into account all the abilities of the child, and permits bright pupils to advance through the school more rapidly than slow or normal pupils; backward and over-age pupils were 


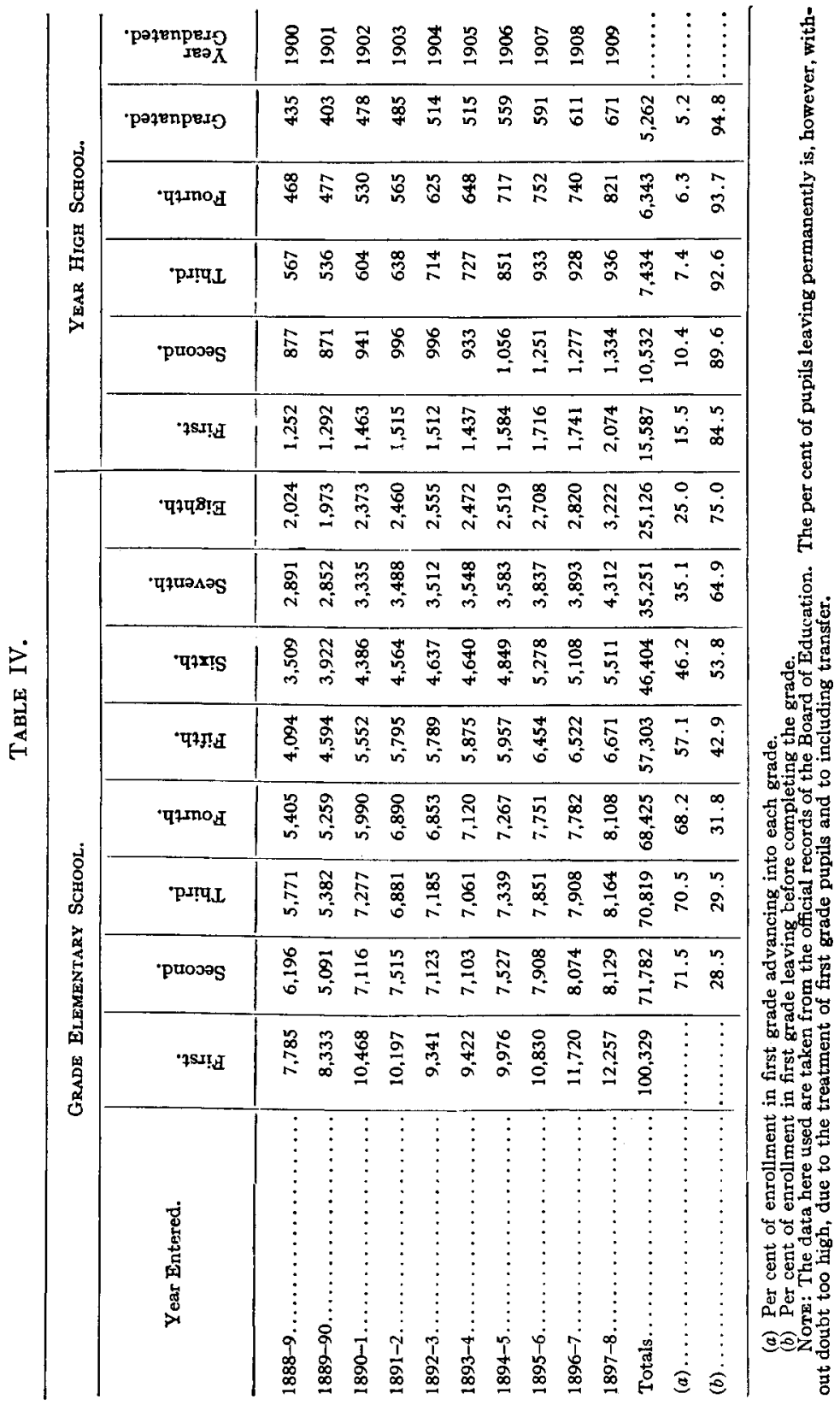


segregated in separate buildings, and a regime and courses of study provided suited to their particular needs; and a system of elementary industrial schools was established for pupils who were fourteen years of age and who had not completed the work of the sixth grade. In the high school, the school day was lengthened and both technical and commercial high schools were opened. That over-age pupils both in the elementary school and in the high school might have opportunity to advance as far as possible in the work of the school

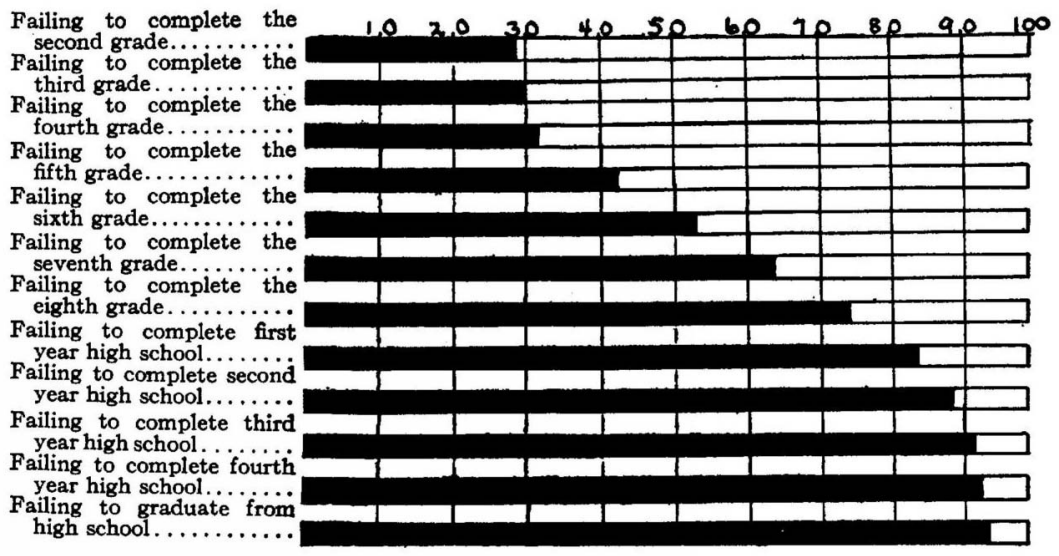

Fig. 4.-Black shows the per cent of pupils enrolled in the first grade of the public schools of Cleveland for the years 1889-98 failing to complete each of the several grades of the elementary school and of the high school.

before dropping out, the school year was shortened to thirty-six weeks-three terms of twelve weeks each, and a summer quarter correlating with the other quarters of the school year, and in which regular school work is done, were instituted. The effects of these and other changes upon the number of pupils withdrawing during the course of the school year, and hence failing to complete in the public school the work of the given grade is shown in Table V. This table shows for the year 1909, and for the year 1910, exclusive of the enrollment in special classes, the per cent of the total enrollment, in each grade of the elementary school and in each class of the high school, withdrawing during the course of the school year. 


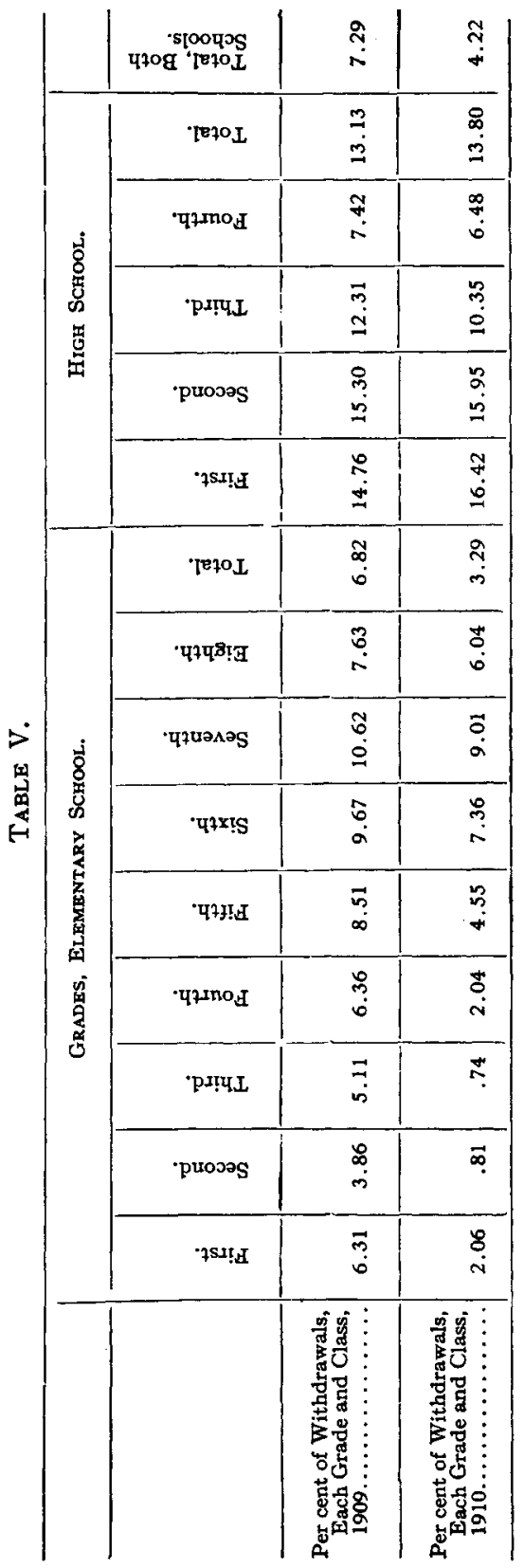




\section{Attaining Efficiency: Improving Instruction}

An efficient city school system must not only hold children in school until they have completed the work of the elementary school, if not of the high school, but, in view of our third standard of efficiency, the quality of instruction must be of the best. There is scarcely a city school system in the country which, within late years, has not been criticised because of the quality of its instruction, particularly in the "three R's." So virulent had this criticism become in Cleveland, that, in 1905, an Educational Commission was appointed to investigate the schools of the city.

The Educational Commission, in order that it might more accurately judge of the work of the schools, gave a spelling test in the winter of 1905, of fifty words to the eighth grade pupils of four schools. The words given were such as, in the mind of the commission, children completing the common school should be able to spell. Of the one hundred and forty-four pupils taking this examination, only one spelled all the words correctly, while the combined errors of the one hundred forty-four were 1,887 , or an average of 13.1 misspelled words per pupil. The Educational Commission made no direct comment upon these results, but a grade of 73.79 per cent was sufficiently suggestive to those in authority.

A careful study was at once made of the time allotted spelling in the daily program of the schools, of the character of the words taught, and of the methods used. As a result of this study, steps were taken to limit spelling to words the child ordinarily uses, to those he hears regularly employed in conversation, to those found in the other studies of the school, and to those the average citizen will find of use in daily life. A system of experiments running through the greater part of a school year was carried on to determine through actual class-room experience what words should be taught and which of these were difficult and which easy for the children. On the basis of the several different reports from each of more than 1,500 teachers, the words to be used in each grade from the third through the eighth were finally fixed upon; these were divided into two groups, principal, or difficult words, and subordinate, or easy words, and arranged into spelling lessons, each lesson consisting of ten words, two principal words and eight subordinate words. Both teachers and pupils were directed to devote most of the spelling period to the mastery of the two principal words and to give but 
minor attention to the subordinate words. Reviews, particularly of the principal words, were made a prominent feature of the instruction. While no change was made in the time assigned spelling in the daily program, teachers were aroused to the importance of spelling, and an interest excited in the children to become good spellers.

On December 10, 1906, there was held what was termed the First Spelling Contest, or the first test of the efficiency of the new work in spelling. This examination consisted of fifty written and five oral words, respectively, for the children of the fifth, sixth, seventh and eighth grades; the test words for each grade were selected from their spelling work for the term. This spelling contest was followed May 24, 1907, by an Annual Contest in which

TABLE VI.

\begin{tabular}{l|c|c|c|c}
\hline & $\begin{array}{c}\text { Pupils } \\
\text { Examined. }\end{array}$ & $\begin{array}{c}\text { Number } \\
\text { of Words. }\end{array}$ & $\begin{array}{c}\text { Average } \\
\text { Number } \\
\text { Misspelled } \\
\text { Words } \\
\text { per Pupil. }\end{array}$ & $\begin{array}{c}\text { Average } \\
\text { Per cent } \\
\text { of Efficiency. }\end{array}$ \\
\hline Commission's Test ${ }^{1} . . .$. & 144 & 55 & 14.414 & 73.79 \\
First Spelling Contest.... & 3,148 & 55 & 7.287 & 86.75 \\
First Annual Contest... & 2,806 & 55 & 6.116 & 88.97 \\
Second Annual Contest.. & 3,494 & 55 & 1.589 & 97.11 \\
Third Annual Contest... & 3,529 & 55 & 1.675 & 96.96 \\
\hline
\end{tabular}

all the children of the four grammar grades participated. The test for each grade consisted of fifty words to be written and five words to be spelled orally, or a total of fifty-five. The words used were selected from the work of the year for the respective grade. Similar annual spelling contests were held March 23, 1908, and May 25, 1909.

Table VI shows the number of children participating in the Educational Commission's test, the number of words given, the average number misspelled per pupil, and the average per cent of efficiency; also the same facts for the first and the three annual contests in the eighth grade.

It will be observed that the average number of misspelled words per pupil in tests of fifty-five words was reduced for the eighth 1Translated into terms of fifty-five words. 
grade from 14.414 to 1.675 , an average decrease per pupil for all eighth grade children of 88.37 per cent. In other words, the children taking the Commission's test in 1905 misspelled on the average 8.6 times more words than the children taking the Annual Contest in 1909.

On the other hand, the average efficiency in spelling, as based upon these tests, which it is believed were equally representative and equally difficult, was raised from 73.97 per cent to 96.99 per cent, an average increase for each child of the eighth grade of 23.17 per cent, which is an average gain in efficiency per pupil of 31.39 per cent.

That the efficiency of the work in spelling might be still further tested, there was given to all eighth grade pupils, May 17, 1909, the spelling examination which was set to the corresponding grade

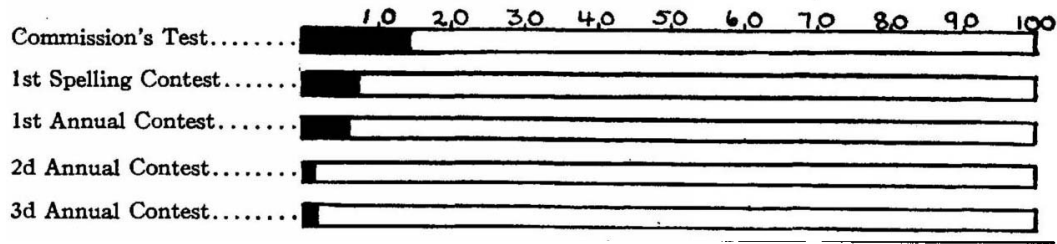

FIG. 5.-Black shows average number of words misspelled per pupil in each test from Educational Commission's Spelling Test, 1905, to Third Annual Spelling Contest, 1909.

of pupils of the Cleveland schools, July, 1858. The test consisted of twenty words. Table VII gives the number of pupils examined, the average number of misspelled words, and the average per cent of efficiency in each case.

TABLE VII.

\begin{tabular}{l|c|c|c}
\hline & $\begin{array}{c}\text { Average } \\
\text { Pupils } \\
\text { Examined. }\end{array}$ & $\begin{array}{c}\text { Aver } \\
\text { Misspelled } \\
\text { Words } \\
\text { per Pupil. }\end{array}$ & $\begin{array}{c}\text { Average } \\
\text { Per cent } \\
\text { of Eficiency. }\end{array}$ \\
\hline Examination of $1858 \ldots \ldots \ldots \ldots \ldots \ldots \ldots$ & 143 & 5.215 & 73.92 \\
Same in $1909 \ldots \ldots \ldots \ldots \ldots \ldots \ldots$ & 3,240 & 4.307 & 78.46 \\
\hline
\end{tabular}

The children of 1909 were at a disadvantage in taking this examination, for the words employed were selected from the spelling 
work of 1858 and were for this reason familiar to the children of that year. Notwithstanding this, the children of 1858 misspelled on the average practically one more word per pupil than those of 1909 , giving the children of 1909 a better average efficiency mark by 4.54 per cent, which represents an average gain in efficiency of 6.12 per cent. In a word, this test not only furnishes evidence of increased efficiency in spelling, but also shows that the children of 1909 were better spellers than the children of 1858 .

\section{Attaining Efficiency: Minimizing the Cost}

Finally, an efficient school system must educate the children of the community at a minimum cost to the taxpayer. Little attention as yet has been given to this aspect of efficiency. In consequence the cost of the same work in a given system may be very much greater in one school than in another.

Table VIII shows the variations in the per capita cost of kindergarten occupation materials for the first half-year of 1910-11, for fifty-six Cleveland schools, also the number of these schools having a given per capita cost:

The facts of Table VIII are significant, not merely because they record the variation in the cost of kindergarten occupation materials, but because they raise important questions: Why are there such variations in cost in the same system? How does the instruction compare in a school where the per capita cost is four cents with the instruction in a school where the per capita cost is sixty-three cents? What is the cost in the schools where the instruction is the best? These questions are significant because they

Test of 1858 $10 \quad 30 \quad 30 \quad 40,50$

Same in 1909 .

FIG. 6.-Black shows per cent of efficiency in Spelling Test given in Cleveland Schools in 1858, and in the same re-given in 1909.

supply, along with data acquired through testing the quality of instruction, the basis of determining what the cost of such material should be, of locating the schools that are spending too little and the schools that are spending too much, and hence, of reducing the cost of such materials in all schools to the lowest point consistent with the best results. 
The facts of Table VIII are also significant because they suggest the lack of standards of cost in education in general, and because they indicate that a school system can only become efficient financially as similar data are collected on each kind of instruction in each kind of school, and as such facts are used, along with data derived from qualitative tests of instruction, to determine standards of cost, and to locate and eliminate financial waste.

TABLE VIII.

\begin{tabular}{|c|c|c|c|}
\hline $\begin{array}{l}\text { Number } \\
\text { of } \\
\text { Schools. }\end{array}$ & $\begin{array}{c}\text { Per Capita Cost of } \\
\text { Kindergarten } \\
\text { Occupation Materials. }\end{array}$ & $\begin{array}{l}\text { Number } \\
\text { of } \\
\text { Schools. }\end{array}$ & $\begin{array}{l}\text { Per Capita Cost of } \\
\text { Kindergarten } \\
\text { Occupation Materials. }\end{array}$ \\
\hline $\begin{array}{l}2 \\
1 \\
1 \\
3 \\
3 \\
2 \\
1 \\
3 \\
1 \\
5 \\
3 \\
1 \\
4 \\
3 \\
1\end{array}$ & 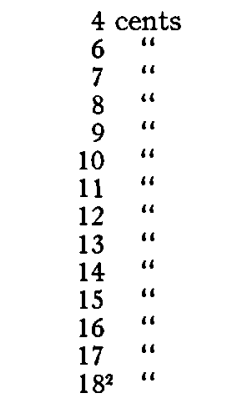 & $\begin{array}{l}3 \\
4 \\
1 \\
1 \\
1 \\
3 \\
3 \\
2 \\
2 \\
2 \\
1 \\
1 \\
1 \\
1\end{array}$ & 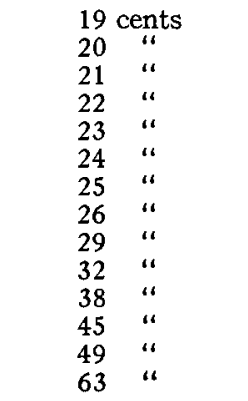 \\
\hline
\end{tabular}

\section{Attaining Efficiency: The Method}

From the foregoing discussion, the main points in the method of attaining efficiency in a city school system may be readily inferred. There is involved, first, the collection of data on the number of children the school should reach, on the number of children the school is reaching, on the amount of schooling the children are actually receiving, on the quality of instruction given, and on the cost; there is involved, second, the interpretation of these facts and their use in fixing upon new administrative plans, in providing new kinds of schools and new courses of instruction, and in devising new methods of teaching; and, third, there is involved the measurement of the results attained through the new plans, the new schools, the new courses, and the new methods, to the end that the data thus derived may be used in judging of their worth and in providing for the further improvement of the system.

2Average per capita cost. 